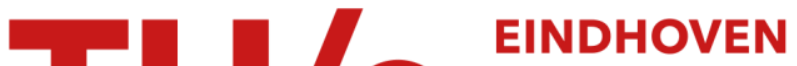 UNIVERSITY OF TECHNOLOGY
}

\section{Kinetics of (co)polymerization at the surface of inorganic submicron particles in emulsion-like systems}

\section{Citation for published version (APA):}

Caris, C. H. M., Kuijpers, R. P. M., Herk, van, A. M., \& German, A. L. (1990). Kinetics of (co)polymerization at the surface of inorganic submicron particles in emulsion-like systems. Makromolekulare Chemie, Macromolecular Symposia, 35-36, 535-548. https://doi.org/10.1002/masy.19900350133

DOI:

10.1002/masy. 19900350133

Document status and date:

Published: 01/01/1990

\section{Document Version:}

Publisher's PDF, also known as Version of Record (includes final page, issue and volume numbers)

\section{Please check the document version of this publication:}

- A submitted manuscript is the version of the article upon submission and before peer-review. There can be important differences between the submitted version and the official published version of record. People interested in the research are advised to contact the author for the final version of the publication, or visit the $\mathrm{DOI}$ to the publisher's website.

- The final author version and the galley proof are versions of the publication after peer review.

- The final published version features the final layout of the paper including the volume, issue and page numbers.

Link to publication

\section{General rights}

Copyright and moral rights for the publications made accessible in the public portal are retained by the authors and/or other copyright owners and it is a condition of accessing publications that users recognise and abide by the legal requirements associated with these rights.

- Users may download and print one copy of any publication from the public portal for the purpose of private study or research.

- You may not further distribute the material or use it for any profit-making activity or commercial gain

- You may freely distribute the URL identifying the publication in the public portal.

If the publication is distributed under the terms of Article 25fa of the Dutch Copyright Act, indicated by the "Taverne" license above, please follow below link for the End User Agreement:

www.tue.nl/taverne

Take down policy

If you believe that this document breaches copyright please contact us at:

openaccess@tue.nl

providing details and we will investigate your claim. 
KINETICS OF (CO)POLYMERIZATIONS AT THE SURFACE OF INORGANIC SUBMICRON PARTICLES IN EMULSION-IIKE SYSTEMS

C.H.M. Caris, R.P.M. Kuijpers, A.M. van Herk and A.L. German* Department of Polymer Chemistry, Eindhoven University of Technology, P.0. Box 513, 5600 MB Eindhoven, The Netherlands

\begin{abstract}
Hydrophilic $\mathrm{TiO}_{2}$ particles were modified with two different titanates and thus made hydrophobic. "Emulsion" polymerizations were carried out in aqueous dispersions of these particles, stabilized with an anionic surfactant. Polymerization kinetics were determined using a densitometer. The effect of several parameters, like surface modification, surfactant and initiator concentration, and stirring speed on polymerizations were studied. Depending on reaction conditions two competitive polymerizations can take place: one in which polymer is formed at the particle surface and one in which free polymer particles are formed. The $\mathrm{TiO}_{2}$ was modified with a titanate containing a methacrylic acid ester, which was used as a comonomer. Thus a chemical bond between $\mathrm{TiO}_{2}$ particles and polymer was obtained. These polymer encapsulated inorganic particles may offer interesting perspectives in those cases, where a good coupling between particles and matrix is important, for instance in latex paints and in polymer composites.
\end{abstract}

INTRODUCTION

$\hat{4}$ By means of emulsion polymerization processes several types of particles with a core-shell morphology can be obtained. We have used an emulsion polymerization-like technique to obtain particles with an inorganic core and a polymer she11. In this paper we describe on-line conversion measurements for these polymerizations, and a qualitative model to explain the observed effects. The surface of $\mathrm{TiO}_{2}$ particles is hydrophilic (Ref. 1) and contains several acidic oH groups, which can react with titanate coupling agents. These organic compounds consist of a central titanium atom, one or two small hydrolysable groups (like 
isopropyl groups) and two or three long hydrophobic chains or functional groups. A reaction can take place in which an alcohol is formed, leaving the titanate coupled to the pigment surface (Ref. 2). The modified, now hydrophobic, particles are dispersed in an aqueous solution of an anionic surfactant, like SDSa) Part of the surfactant is adsorbed at the particle surface, forming a micelle-like structure in which an "emulsion polymerization" can be carried out. By using a titanate containing a copolymerizable group the modified $\mathrm{TiO}_{2}$ can be used as a comonomer for polymerization, and a chemical bond between polymer and particle can be obtained. Polymerization kinetics can be studied on line using a densitometer based on oscillatory frequency.

The encapsulated inorganic particles may offer perspectives as pigments in latex paints, where they provide a better coupling between pigment and binder (preventing agglomeration of the pigment, thus improving film properties and gloss), but also as fillers for polymer composites, in flame retardants and as carriers for catalysts.

\section{EXPERIMENTAL}

The experiments were carried out with pure rutile (Kronos, RLK). This material was washed with distilied water, in order to remove some $\mathrm{K}_{2} \mathrm{SO}_{4}$, adsorbed at the surface, and dried under vacuum at $130^{\circ} \mathrm{C}$ before use. Titanate coupling agents $\mathrm{KR} 7$ (diisopropyl isostearoyl methacryloyl titanate) and KRTTS (diisopropyl diisostearoyl titanate) of Kenrich Petrochemicals Inc. were used without further purification. Modification of $\mathrm{TiO}_{2}$ was carried out in dichloromethane (Merck p.a.): $30 \mathrm{~g} \mathrm{TiO}_{2}$ and $30 \mathrm{~g}$ glass pearls were added to the flask containing the titanate dissolved in $\mathrm{CH}_{2} \mathrm{Cl}_{2}$ in a concentration of about $2 \mathrm{~g} / 1$. It is possible to use a mixture of both titanates, but first adding KR7 and afterwards KRTTS proved to be more effective. The total amount of titanates applied always was 1,0 wt\% of the $\mathrm{TiO}_{2}$. The reaction mixture was shaken vigorously for about two hours. Then the glass pearls were removed by filtration and the modified $\mathrm{TiO}_{2}$ was isolated by centrifugation. The product was washed three times with solvent, and dried at room temperature. Stability of the titanates at the particle surface against solvolysis was studied by means of conductometry (using a radiometer CDM 80 conductivity meter).

a) sodium dodecylsulfate 
Polymerizations, were carried out with methyl methacrylate (Merck p.a.) distilled at reduced pressure under nitrogen to remove the inhibitor, and a radical initiator based on 4,4'-azobis (4-cyanovaleric acid). (ACPA) (Fluka A.G., purum). Because of its limited solubility in water we decided to use the sodium salt instead of the acid (prepared by reacting the acid with two equivalents of sodium methanolate in methanol). Dispersions of modified $\mathrm{TiO}_{2}$ in an aqueous solution of sodium dodecylsulfate (SDS, Fluka Chemie A.G., puriss) were made with an Ystral type $X 1020$ high shear stirrer. A small amount of 2-propanol (Merck, p.a.) was added to prevent foaming, and also as an internal standard for monomer conversion measurements by means of gas chromatography. The mixture was added to a 1 liter double-walled thermostated reaction vessel, and flushed with nitrogen in order to remove oxygen. Then monomer was added, and the total mixture was thermostated at $58^{\circ} \mathrm{C}$. The initiator was added, dissolved in $10 \mathrm{ml}$ distilled water. The reaction mixture was continuously pumped through the external cel1 (DMA $401 \mathrm{~W}$ ) of an Anton Paar Densitometer (DMA 55) by means of a peristaltic pump (flow: ca. 45 $\mathrm{ml} / \mathrm{min}$, internal diameter of the buty 1 rubber tubes $2 \mathrm{~mm}$ ). Just before entering the densitometer the mixture passed through a heat exchanger inside the cell, thermostated at exactly the same temperature as the reaction vessel, to compensate for any possible heat losses during transport. The temperature during polymerization did not vary more than $0,05^{\circ} \mathrm{C}$.

The reaction vessel was kept under a slight excess pressure of nitrogen ( $\pm 0,2$ bar) which enabled us to take samples during polymerization. The samples were collected in a flask containing a known amount of hydroquinone to immediately stop the reaction, and their dry solids content was determined. Both methods described (dry solids content of the mixture and its density) were used to calculate conversion-time curves.

\section{RESULTS AND DISCUSSION}

\section{Modification of $\mathrm{TiO}_{2}$ with titanates}

The $\mathrm{TiO}_{2}$ used consists of pure crystalline rutile particles with a z-average diameter of $260 \mathrm{~nm}$, a specific surface area of $7,7 \mathrm{~m}^{2} / \mathrm{g}$ and a total pore volume of $0,58 \mathrm{~cm}^{3} / \mathrm{g}$. According to ESCA the particle surface consists of pure $\mathrm{TiO}_{2}$. It is modified with titanates according to Figure 1. The chemical structure and stability of these titanates were studied before (Refs. 1-2).

a) $\mathrm{ESCA}=$ Electron Spectroscopy for Chemical Analysis 


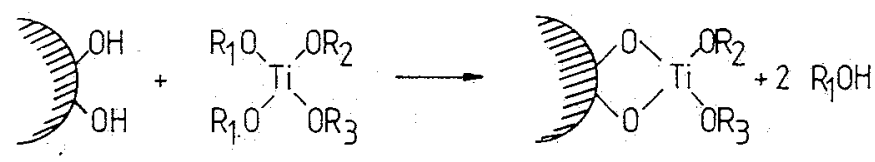

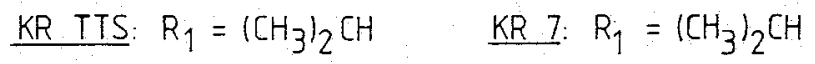

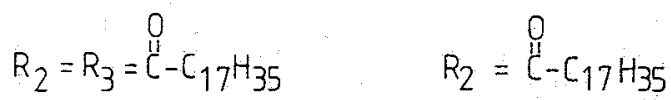

$R_{3}=\stackrel{0}{\mathrm{H}}-\mathrm{C}_{1}=\mathrm{CH}_{2}$

$\mathrm{CH}_{3}$

Figure 1. Modification of $\mathrm{TiO}_{2}$ surface with titanates.

KRTTS contains two long hydrophobic chains that form a hydrophobic mantle round the particle, thus repeling water from the hydrolysable moieties near the particle surface when the $\mathrm{TiO}_{2}$ is dispersed in water. KR7 only contains one hydrophobic group and therefore is less effective in protecting itself against hydrolysis. By using a mixture of both titanates it is possible to protect the methacrylic acid ester of KR7 at the particle surface against hydrolysis. Best results were obtained by first modifying the $\mathrm{TiO}_{2}$ with a small amount of $\mathrm{KR} 7$, and af terwards with a complementary amount of KRTTS, the total weight percentage of titanate applied being $1 \%$. In this paper we describe polymerizations of MMA a) the surface of these modified $\mathrm{TiO}_{2}$ particles. In the case of KRTTS a physical bond between inorganic particle and polymer can be formed. In the case of KR7 the methacrylic acid ester can be considered as a comonomer for polymerization, and thus also a chemical bond between polymer and $\mathrm{TiO}_{2}$ can be obtained. This can result in a higher polymer content of the

a) methyl methacrylate 
inorganic particles: in the case of $\mathrm{TiO}_{2}$ modified with 0,50 wto $\mathrm{KR} 7$ and 0,5 wto KRTTS 8,3 wt\%, and in the case of $\mathrm{TiO}_{2}$ modified with $0,80 \mathrm{wt} \%$ KR7 and 0,20 wto KRITS, 10,5 wto was found (weight ratio $\mathrm{TiO}_{2}:$ MMA $=1: 3$ ).

on-1ine conversion measurements

Oscillator based densitometers have been used before for monitoring emulsion polymerizations (Refs. 3-5). Normally it is assumed that the specific volumes of the reaction components are additive and that by mixing no changes in volume occur. Under these assumptions a linear relationship between the specific volume of the reaction mixture and monomer conversion should exist. We studied this relationship for our polymerization systems, in which the differences between the densities of the various components are extremely large (density of $\mathrm{TiO}_{2}$ is $4,2 \mathrm{~g} / \mathrm{cm}^{3}$, density of MMA $\left.=0,944 \mathrm{~g} / \mathrm{cm}^{3}\right)$. In Figure 2 the specific volume of the total mixture is shown as a function of monomer conversion under various circumstances. The conversion was calculated from the dry solids content of samples taken during polymerization. The polymerizations carried out in this experiment are specified in Table 1.

Table 1. Polymerizations used to study the specific volume of the reaction mixture as a function of conversion under various conditions.

\begin{tabular}{lcclll}
$\begin{array}{c}\text { Reaction } \\
\text { Weight ratio } \\
\text { KRTTS:KR7 }\end{array}$ & $\begin{array}{c}\text { [SDS } \\
(\mathrm{g} / 1)\end{array}$ & $\begin{array}{l}\text { [ACPA] } \\
(\mathrm{mmo1} / 1)\end{array}$ & $\begin{array}{l}\text { [MMA] } \\
(\mathrm{mo1} / 1)\end{array}$ & $\begin{array}{c}\text { Stirring } \\
\text { rpm }\end{array}$ \\
\hline & & & & & \\
1 & $1: 1$ & 3,0 & 2,80 & 0,91 & 200 \\
2 & $1: 4$ & 3,0 & 2,70 & 0,90 & 200 \\
3 & $1: 1$ & 2,7 & 2,46 & 0,90 & 250 \\
4 & $1: 1$ & 2,4 & 2,78 & 0,90 & 250 \\
5 & $1: 1$ & 2,0 & 2,76 & 0,90 & 250
\end{tabular}

The $\mathrm{TiO}_{2}$ content of the mixtures described in this paper was $30,0 \mathrm{~g} / 1$. 


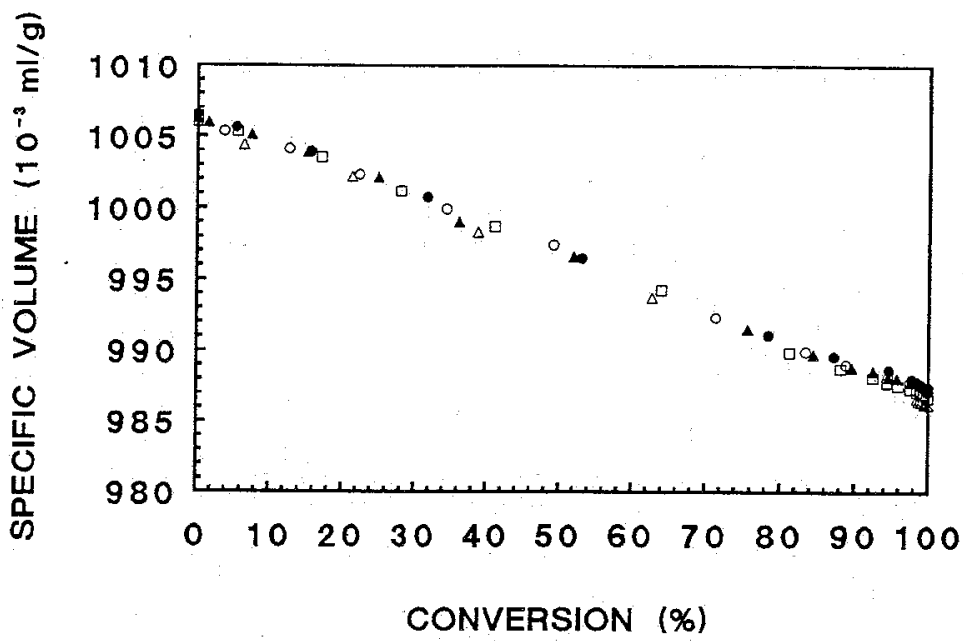

Figure 2. Specific volume of the emulsion as a function of monomer conversion.

- Reaction 1, $\Delta$ Reaction 2, o Reaction 3, a Reaction 4, $\triangle$ Reaction 5 .

According to Figure 2 there is a linear relationship between specific volume and conversion in all these sytems, independent of reaction conditions like surfactant- or initiator concentration, modification of $\mathrm{TiO}_{2}$ with different titanates, and stirring speed. Only at very high conversions a small deviation from linearity can be observed, probably caused by volume contraction if monomer is only present in swollen particles (in this stage of the polymerization all monomer droplets will have disappeared). From these experiments it can be concluded that even in this heterogeneous system monomer conversion can be calculated according to the equation derived by F.J. Schork and W.H. Ray (Ref. 4).

$$
x=\frac{\left(1 / \rho_{e}^{0}-1 / \rho_{e}\right)}{\left(1 / \rho_{e}^{0}-1 / \rho_{e}^{0}\right)}
$$

where $X$ is the conversion, $\rho_{e}$ the density of the reaction mixture and $\rho^{\circ} \mathrm{e}$

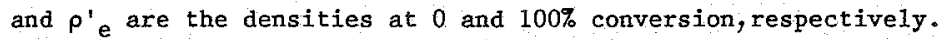


"Emulsion Polymerizations" of MMA in the presence of modified $\mathrm{TiO}_{2}$

When hydrophobic $\mathrm{TiO}_{2}$ particles are dispersed in an aqueous solution of, for instance, SDS, part of the surfactant molecules is adsorbed at the particle surface (Ref. 2). Thus a micelle-like structure with an inorganic particle in the core is formed, in which monomer can be adsorbed. During polymerization the inorganic particle will be encapsulated by a polymer layer. The polymer can be physically bound to the particle and the titanates, but by using a titanate containing a copolymerizable group (1ike KR7) also a chemical bond between polymer and $\mathrm{TiO}_{2}$ can be obtained. At a surfactant concentration above cmc also "free" micelles, that do not contain an inorganic core, are present, in which polymerization can occur simultaneously, Both polymerizations are competitive as they both need monomer and also surfactant for stabilization. Probably surfactant concentration will play a very important role in the reaction mechanism and kinetics, as was already described for polymerizations on $\mathrm{TiO}_{2}$ particles modified with KRTTS (Refs. 1-2). Growing particles, consisting of pure polymer and absorbed monomer, are easily penetrated by monomers, oligomers and radicals, so when a second radical enters the particle immediate termination with the first radical will occur. Therefore, neglecting any possible desorption phenomena, the average number of radicals in such particles ( $\bar{n}$ ) is $1 / 2$ ("zero-one system"). In the case of encapsulated $\mathrm{TiO}_{2}$ particles the inorganic core cannot be penetrated by radicals, so probably these particles can contain more than one radical at the same time $(\bar{n}>1)$. The average life time of radicals at the inorganic surface will be longer than the average life time of radicals in normal polymer particles. Using equation (1) conversion-time curves were calculated from density data obtained for polymerizations at different stirring speeds. As shown in Figure 3 there is an extremely good agreement between the results obtained by this method and the conversion calculated from the dry solids content of the reaction mixture. As expected from Figure 2 only at very high conversions a slight deviation is observed.

a) the critical micelle concentration 


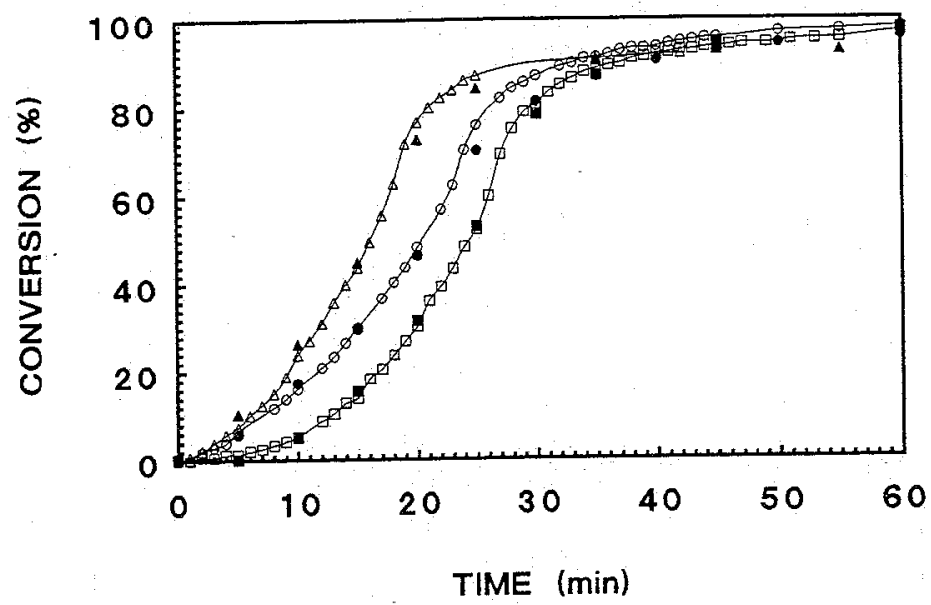

Figure 3. Effect of stirring rate on polymerization kinetics.

(MMA concentration $=0,90 \mathrm{~mol} / 1 ; \mathrm{ACPA}$ conc $=3,0 \mathrm{mmol} / 1$; SDS conc. $=3,0 \mathrm{~g} / 1 ; \mathrm{TiO}_{2}$ modified with 0,5 wto $\mathrm{KR} 7$ and 0,50 wt\% $\mathrm{KRTTS}$ ). biack symbols: according to the dry solids content of the mixture. Open symbols: according to the density of the mixture. 口 $200 \mathrm{rpm}, 0250 \mathrm{rpm}, \Delta 400 \mathrm{rpm}$.

From Figure 3 it also can be concluded that an increase in stirring rate results in an increase in polymerization rate. In emulsion polymerizations of ten the opposite effect is observed (Refs. 6-7), but if polymerization can only take place in a small layer at the particle surface (because, like in the case of vinylidene chloride (Ref. 7), the polymer cannot be swollen by its monomer) the same effect is found. This behaviour can be explained by a better dispersion of the $\mathrm{TiO}_{2}$ particles at a higher stirring rate. Because of this effect a large particle surface is available for polymerization and more radicals will be captured by the $\mathrm{TiO}_{2}$ particles. Since at their surface termination by other radicals is less probable, the total number of radicals in the system increases, resulting in a higher polymerization rate. 


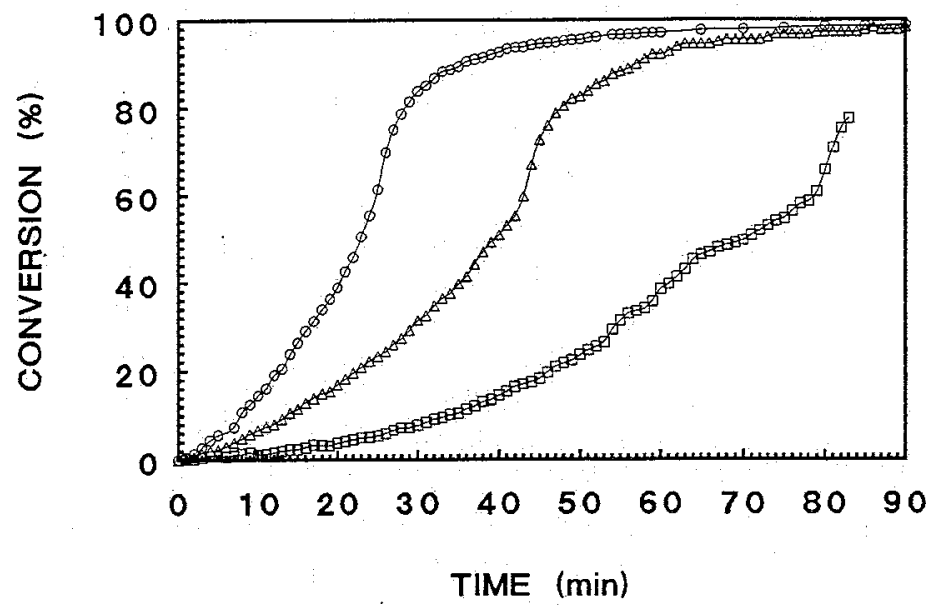

Figure 4. Effect of initiator concentration on polymerization kinetics. (MMA concentration $=0,90 \mathrm{~mol} / 1 ; \operatorname{SDS}$ conc. $=2,4 \mathrm{~g} / 1$;

Stirring rate $250 \mathrm{rpm} ; \mathrm{TiO}_{2}$ modified with 0,50 wt: $\mathrm{KR} 7$ and 0,50 wto KRTTS).

$\square$ ACPA conc. $=2,15$ mino $1 / 1, \Delta 2,46 \mathrm{mmol} / 1,02,78 \mathrm{mmol} / 1$.

The initiator concentration appears to have a very large influence on polymerization kinetics as shown in Figure 4. In this case at about $45 \%$ conversion a temporary decrease in reaction rate can be observed, followed by a sharp increase. Especially at low initiator concentrations this effect is very clear. In order to avoid the formation of pure polymer particles the surfactant concentration was kept slightly above $\mathrm{cmc}$ in this system. Probably during the first part of the polymerization two competitive polymerizations take place: one in free micelles and one at the surface of the modified $\mathrm{TiO}_{2}$ particles. As all these growing particles need surfactant for stabilization after a while a deficiency of surfactant will arise, resulting in agglomeration of the encapsulated $\mathrm{TiO}_{2}$ particles. Since they contain a relatively large part of the radicals present in the system, polynerization rate will decrease as these radicals get trapped inside the agglomerates. New radicals are being generated in the water phase and they will cause an increase in 
polymerization rate after some minutes. Now polymerization will continue mainly in free polymer particles, formed during the first part of the reaction, and in new particles, formed after the release of surfactant molecules when agglomeration occurs. At a low initiator concentration this effect is more important as the $\mathrm{TiO}_{2}$ particles contain a relatively larger part of the radicals present in the system (less free polymer particles are formed). If we assume that during the first part of the polymerization reaction mainly takes place at the $\mathrm{TiO}_{2}$ surface, these experiments can be compared with a seeded emulsion polymerization. However, until $20 \%$ conversion polymerization rate is proportional to the 5 th power of the initiator concentration, and between 30 and $40 \%$ conversion to the 3 rd power. In comparison with a normal emulsion polymerization this is extremely high. The assumption of a "seeded polymerization" is not really justified as the $\mathrm{TiO}_{2}$ particles can only adsorb a very small amount of monomer in a thin layer at the particle surface, and, according to transmission electron microscopy, during this period also particles will be formed by "normal" emulsion polymerization. Because, according to Dark Field Microscopy, also during this period some aggiomeration of (encapsulated) particles occurs, the contribition of the normal emulsion polymerization to the polymerization rate will become more important, resulting in the decrease in initiator concentration dependence as observed. After the temporary slowdown the initiator concentration shows on $1 y$ a very small influence on polymerization rate, as expected for an emulsion polymerization. The sharp increase in rate may be explained by the "gel" effect (Ref. 8) or by a net increase of the number of particles.

From the above it can be expected that the surfactant concentration plays a very important role in the kinetical behaviour of these polymerizations. As shown in Figure 3 , at surfactant concentrations far above cmc, no special effects are observed. However, a decrease in surfactant concentration appears to influence kinetics during the first part of the polymerization, and, at about the critical micelle concentration $(2,0 \mathrm{~g}$ SDS $/ 1$ in this system) also a temporary decrease in polymerization rate at $36 \%$ conversion is observed (Figure 5). Similar kinetics have also been observed for polymerizations at the surface of hydrophobic $\mathrm{TiO}_{2}$, determined by means of gas chromatography. Also in this case agglomeration of the encapsulated particles may account for the 
effect. At high surfactant concentrations the temporary slowdown is not observed, partly because of a better stabilization of the inorganic particles, and partly because the contribution of the normal emulsion polymerization to the conversion-time curves becomes more important, as the number of free micelles increases. In the second part of the polymerization, when reaction mainly takes place in polymer particles, only a small influence of surfactant concentration on polymerization rate can be observed.

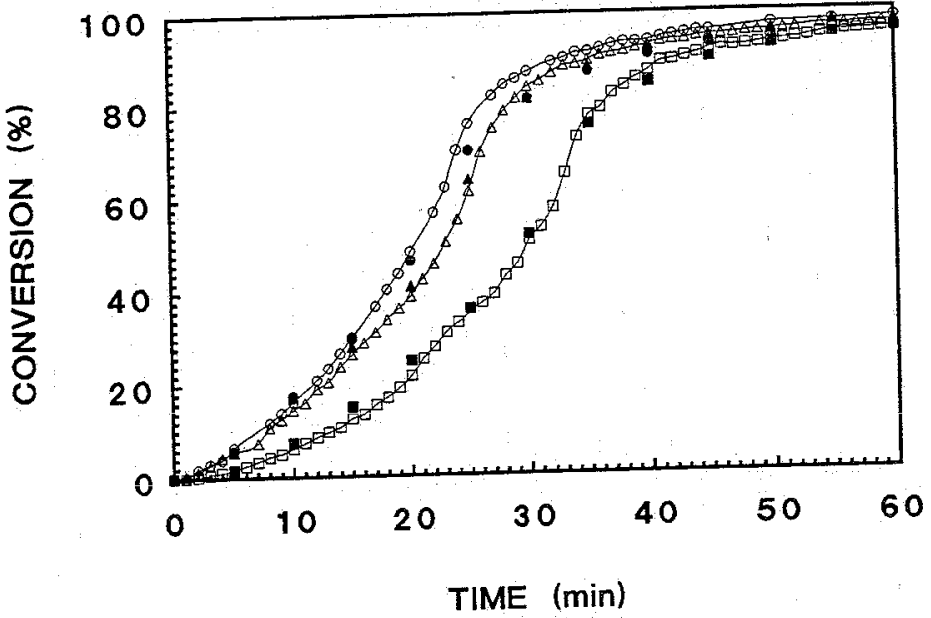

Figure 5. Effect of surfactant concentration on polymerization kinetics. (MMA concentration $=0,90 \mathrm{~mol} / 1 ; \mathrm{ACPA}$ conc $.=2,8 \mathrm{mmo} 1 / 1$; Stirring rate $250 \mathrm{rpm} ; \mathrm{TiO}_{2}$ modified with 0,50 wto $\mathrm{KR} 7$ and 0,50 wt\% KPTTS).

Black symbols: according to the dry solids content of the mixture. White symbols: according to the density of the mixture. $\square$ SDS conc $=2,0 \mathrm{~g} / 1, \Delta 2,4 \mathrm{~g} / 1, \circ 3,0 \mathrm{~g} / 1$.

In order to prevent agglomeration of the encapsulated $\mathrm{TiO}_{2}$ particles, without favouring polymerization in free micelles by, for example, adding extra surfactant, the monomer concentration was decreased from 0,90 to $0,30 \mathrm{~mol} / 1$. Because of the absence of "large" agglomerates both the polymerization at the $\mathrm{TiO}_{2}$ surface and the polymerization in free micelles took place during the entire course of the polymerization, and no temporary decrease in reaction rate could be observed (Figure 6). 


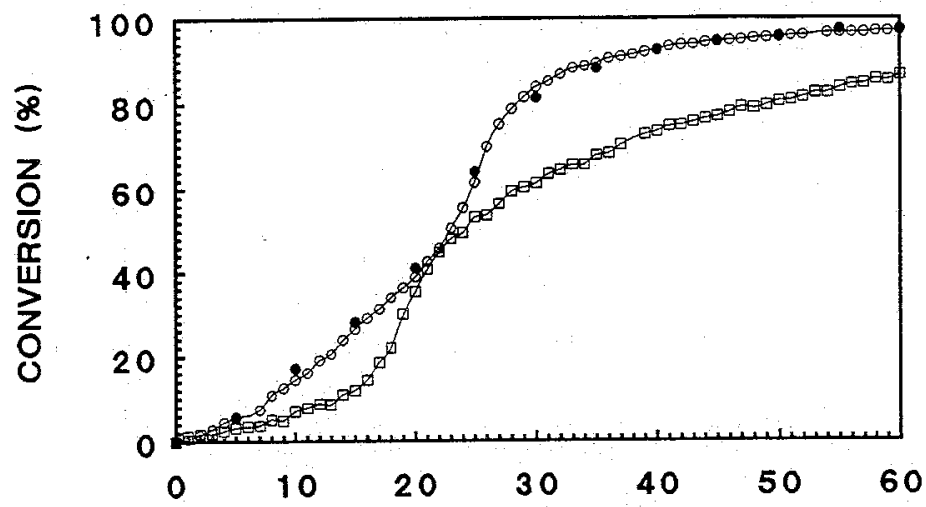

TIME (min)

Figure 6. Effect of monomer concentration on polymerization kinetics. (ACPA conc. $=2,8$ mol $/ 1 ;$ SDS conc $=2,4 \mathrm{~g} / 1 ;$ stirring rate $=$ $250 \mathrm{rpm}$ ):

Black symbols: according to the dry solids content of the mixture. White symbols: according to the density of the mixture. $\square$ MMA conc. $=0,30$ mol $1 / 1$ ( $\mathrm{TiO}_{2}$ modified with 0,66 wt: KR7 and 0,34 wt응 KRTTS).

0 MMA conc. $=0,90$ mo1/1 $\left(\mathrm{TiO}_{2}\right.$ modified with $0,50 \mathrm{wt} / \mathrm{KR} 7$ and 0,50 wt: KRIIS)

The final decrease in reaction rate, for most polymerizations at about $80 \%$ conversion, was now observed already at $40 \%$ conversion. This can be expected, because at this conversion all monomer droplets will have disappeared, as the water solubility of MMA is about 0,15 moti 1 . Because less agglomeration occurred, the $\mathrm{TiO}_{2}$ particles were better encapsulated by polymer and a larger percentage of the polymer was formed at the particle surface $\left(4,3 \%\right.$ instead of $2,7 \%$ when the weight ratio $\mathrm{TiO}_{2}$ : MMA is lowered from $1: 3$ to $1: 1$ for $\mathrm{TiO}_{2}$ modified with equal amounts of KR7 and KRTTS). 


\section{CONCLUSIONS}

Polymerizations can be carried out in aqueous dispersions of modified, hydrophobic, submicron inorganic particles (like $\mathrm{TiO}_{2}$ pigments), stabilized with, for instance, sodium dodecylsulfate. Polymerization can take place at the particle surface, resulting in a particle with an inorganic core and a polymer shell. By using a copolymerizable titanate coupling agent at the $\mathrm{TiO}_{2}$ surface a chemical bond between particle and polymer can be established. The dispersions show very good stability and, as a result of this, polymerizations can be monitored on-line using a densitometer. There is a linear relationship between the specific volume of the emulsion and the monomer conversion (independent of reaction conditions), and therefore conversion can easily be calculated from density data. Conversion-time curves obtained in this way showed a remarkably good resemblance with those obtained by conventional methods (1ike the determination of the dry solids content of the mixture). This method enabled us to study the kinetic behaviour of our polymerizations very accurately, and on-line. The polymerizations show very interesting kinetics, highly influenced by variation of initiator or surfactant concentration. Depending on reaction conditions two competitive polymerizations can take place: one at the particle surface and one in free micelles. Both polymerization phenomena are strongly interrelated, in which agglomeration plays a very important role. This agglomeration can be prevented by using low monomer concentrations, resulting in a stable product and a better encapsulation of the $\mathrm{TiO}_{2}$ particles.

\section{ACKNOWLEDGEMENT}

The authors wish to acknowledge financial support by the "Onderzoekstimuleringscommissie Verf (OSV)".

\section{REFERENCES}

(1) G.H.M. Caris, L.P.M. v. Elven, A.M. v. Herk, A.L. German, "Polymerization at the Surface of Inorganic Submicron Particles" presence and Future in Science and Technology of Coatings and their Components, ed. E. Moeller, Ungeheuer und Ulmer $\mathrm{Kg} \mathrm{GmbH}$, Ludwigsburg, vo1. $\underline{3}, 341,1988$ 
(2) C.H.M. Garis, L.P.M. v. Elven, A.M. v. Herk, A.L. German, British Polymer Journa1, 21, no. 2, 133 (1989)

(3) K.J. Abbey, "Polymerization Kinetics by Precision Densimetry" Emulsion Polymers and Emulsion Polymerization, ed. M.J. Comstock, Am. Chem. Soc., Washington D.C., 345, 1981

(4) F.J. Schork, W.H. Ray, "On-line Monitoring of Emulsion Polymerization Reactor Dynamics" Emulsion Polymers and Emulsion Polymerization, ed. M.J. Comstock, Am. Chem. Soc., Washington D.C., 505, 1981

(5) F.J. Schork, "Continuous Monitoring of Emulsion Polymerization Systems", Science and Technology of Polymer Colloids, ed. G.W. Poehlein, R.H. Ottewill, J.W. Goodwin, Martinus Nijhoff Publishers, The Hague, 188,1983

(6) M. Nomura, M. Harada, W. Eguchi, S. Nagata, J.Appl.Polym.Sci.., 16, 835 (1972)

(7) C.P. Evans, P.M. Hay, I. Marker, R.W. Murray, 0.J. Sweeting, J. Appl. Polym.Sci, 13, 39 (1961)

(8) M. Konno, K. Himizu, K. Arai, S. Arai, J.Polym.Sci.: Part A: Polym.Chem., 25, 223 (1987) 